\title{
Estratégias Competitivas na Área da Saúde no Brasil: um Estudo Exploratório
}

\section{Competitive Strategy in the Health Care Sector: an Exploratory Study}

\author{
Moisés Ari Zilber* \\ Doutor em Administração pela USP. \\ Professor da Universidade Presbiteriana Mackenzie, São Paulo/SP, Brasil. \\ Luiz Carlos Lazarini \\ Mestre em Administração de Empresas pela Universidade Presbiteriana Mackenzie, \\ São Paulo/SP, Brasil.
}

*Endereço: Rua da Consolação, 930, Edifício Modesto Carvalhosa, São Paulo/SP, 01302907.E-mail:mazilber@mackenzie.com.br 


\title{
Resumo
}

Este estudo, de caráter exploratório, visou avaliar as estratégias utilizadas pelas operadoras do setor de planos de saúde. Foi desenvolvido por meio de pesquisa de campo quantitativa, fundamentada na aplicação de questionário estruturado, utilizando-se uma escala do tipo Likert. Com base em amostra probabilística no segmento de planos de saúde para pessoas físicas residentes no município de São Paulo, procurou-se identificar dentre o conjunto de vantagens competitivas, citadas no referencial teórico, quais são as que mais influenciam os usuários no momento de escolha da marca do plano de Saúde. Da aplicação de técnicas estatísticas descritiva e multivariada resultou que Agilidade, Atendimento, Marca, Pioneirismo e Porte foram os fatores mais importantes. O artigo apresenta uma pesquisa bibliográfica sobre estratégia, vantagem competitiva, fontes de vantagem competitiva e aspectos de sua sustentabilidade; metodologia; resultados e limitações e recomendações para estudos futuros. Tendo em vista as mudanças ocorridas neste setor após a nova legislação, as quais têm exigido grande esforço por partes da empresas operadoras para se adaptar ao novo cenário competitivo, o presente estudo levanta questões estratégicas importantes para serem consideradas no futuro.

Palavras-chave: estratégia; vantagem competitiva; plano de saúde; agilidade e serviços.

\begin{abstract}
This is an exploratory study and its main objective was to evaluate strategies adopted in the Brazilian health care sector. It was developed under a quantitative sample based on application of a structured questionnaire with questions determined on a Likert model. Based on a probabilistic sample selected among people that have health care plans in São Paulo city the research had the objective to identify competitive advantages that usually have more influence in the chosen process of Health Maintenance companies by consumers. Multivariate and descriptive statistics techniques were used and the study concluded that Agility, Attendance, Brand, Pioneers and Size of the company would be the most important factors. This article discusses the theory about strategy, competitive advantage, sources of competitive advantage and sustainability of the competitive advantages. It also includes the methodology procedures, the results and the limitations and recommendations for future studies. Considering the new rules for health care business and how these modifications are reflecting on the competitive scenario this study have discussed strategic questions that should be reevaluated in the future.
\end{abstract}

Key words: strategy; competitive advantage; health care; agility; service. 


\section{INTRODUÇÃO}

Porter (1989) entende que o objetivo da estratégia é estabelecer para a empresa uma posição competitiva perante a concorrência. Esta posição inclui vantagens competitivas que garantam a preferência dos clientes e que sejam sustentáveis ao longo do tempo. A vantagem competitiva surge quando a empresa consegue criar para seus clientes um valor que supere o seu custo de fabricação.

O setor de planos de saúde é caracterizado por uma concorrência acirrada entre empresas de medicina de grupo, empresas de seguro saúde e as cooperativas médicas. Conforme dados da Agência Nacional de Saúde, em maio de 2004 estavam registradas como operadoras neste segmento 1.159 empresas. Embora seja um setor controlado com diversas normas e procedimentos, há uma variedade de estratégias quanto a produtos (rede assistencial), preços e ações promocionais que as operadoras utilizam.

Segundo dados da ANS, da população total do Brasil, 35 milhões são cobertos pelo sistema de saúde suplementar, que é composto pelas operadoras de planos de saúde. Destes usuários, $70 \%$ estão cobertos por planos corporativos ou empresariais (as empresas contratam os serviços de assistência médica para seus funcionários), e $30 \%$ são planos de pessoas físicas.

O objetivo do estudo foi avaliar, dentro da realidade empresarial brasileira, quais são as fontes de vantagem competitiva que influenciam a decisão de compra de um plano de saúde pelos clientes.

Assim, a pergunta que representa o problema deste estudo é quais fontes de vantagem competitiva, na opinião dos clientes, influenciam a escolha da empresa prestadora de serviços de assistência médica?

\section{TEORIA}

\section{Estratégia}

Whittington (2002) classifica as estratégias segundo quatro escolas: a clássica, a evolucionária, a processual e a sistêmica. Para os clássicos, o planejamento é processo racional, a longo prazo, que deve priorizar a lucratividade máxima. Alfred 
Sloan, ex-presidente da General Motors, de acordo com Whittington, foi um dos precursores desta escola. Sloan defendia que o problema estratégico fundamental devia ser o posicionamento da empresa nos mercados em que se poderiam alcançar os maiores índices de lucratividade. Outros autores desta escola citados por Whittington foram Alfred Chandler e Igor Ansoff.

A escola evolucionária acredita que é o ambiente que faz a seleção da melhor estratégia e não os gerentes através de processos formais de planejamento. Um dos defensores deste enfoque é Bruce Henderson, fundador do Boston Consulting Group, que usou a teoria de Darwin para explicar a sobrevivência das empresas, traçando um paralelo entre a concorrência econômica e a lei das selvas. De acordo com os evolucionistas, as empresas devem desenvolver sua capacidade adaptativa para enfrentar os desafios do mercado. Como o mercado é muito imprevisível, os estrategistas devem manter custos baixos e opções abertas para aproveitar as oportunidades (Whittington, 2002).

Os processualistas entendem que as estratégias eficientes estão relacionadas ao conhecimento profundo das operações e das forças básicas da organização. Para eles, como as organizações e os mercados são desordenados, não adianta os estrategistas buscarem o ideal. O melhor é aceitar o mundo como ele é e se concentrar na eficiência da empresa. Whittington (2002) destaca, como representantes desta escola, Hamel, Prahalad e Mintzberg.

A respeito da escola sistêmica, Whittington (2002) comenta que as estratégias refletem os sistemas sociais em que a empresa atua. Diferenças no mercado, classes sociais, Estados e sistemas culturais interferem no processo estratégico. Portanto os teóricos sistêmicos defendem uma relativização das estratégias de acordo com a natureza dos sistemas sociais.

Segundo Porter (1989), a estratégia compreende a construção de defesas contra os concorrentes ou a descoberta de posições no setor cujas forças competitivas sejam menos vulneráveis. O desenvolvimento de uma estratégia competitiva tem como finalidade básica a definição do modo como a empresa irá competir no mercado. A definição deste posicionamento é bastante afetada pela estrutura da indústria, aqui entendida como o grupo de empresas que fabricam produtos substitutos entre si. A estratégia tem por objetivo definir uma posição, baseada em vantagens competitivas, que seja lucrativa e ao mesmo tempo sustentável, contra o ataque dos concorrentes.

Henderson (1989) confirma o conceito de Porter, quando destaca que a estratégia visa a estabelecer planos de ação que desenvolvam novas vantagens competitivas ou que aumentem o escopo das vantagens competitivas atuais da organização. 
Seguindo a mesma linha de raciocínio, Mintzberg, Ahlstrand e Lampel (2000) afirmam que a estratégia é o ponto alto da atividade dos executivos, razão pela qual tem sido, nas duas últimas décadas, um tema extensamente estudado no meio acadêmico. Para os autores, o conceito de estratégia inclui pelo menos cinco definições: estratégia é plano; estratégia é padrão ou comportamento consistente ao longo do tempo; estratégia é posição escolhida pela empresa para seus produtos em determinado mercado; estratégia é perspectiva, isto é, a maneira como a empresa faz as coisas; e a estratégia é truque ou manobra para enganar os concorrentes.

A estratégia visa a criar novas vantagens competitivas sustentáveis ou melhorar as vantagens competitivas atuais da empresa para que ela enfrente com sucesso a concorrência (Henderson, 1989; Porter, 1989).

\section{Vantagem Competitiva}

O conceito de vantagem competitiva está, assim, intimamente relacionado à estratégia e ao tema competição, como destacam Henderson (1989) e Porter (1989). Houve também uma evolução desse conceito ao longo da história da administração, que implicou diferentes formas de abordagem acerca do mesmo tema.

Porter (1989) entende que o objetivo da estratégia é estabelecer para a empresa uma posição competitiva perante a concorrência. Esta posição inclui vantagens competitivas que garantam a preferência dos clientes e que sejam sustentáveis ao longo do tempo. A vantagem competitiva surge quando a empresa consegue criar para seus clientes um valor que supere o seu custo de fabricação. Para o autor, há dois tipos gerais de vantagem competitiva: a liderança de custos e a diferenciação. Uma terceira alternativa ocorre quando a empresa seleciona um segmento específico do mercado que será focado com uma estratégia de custos ou de diferenciação.

Ainda, segundo ele, por meio da estratégia de liderança de custos, a empresa se torna o produtor de menor custo em seu setor, tendo como principais fontes de vantagem competitiva a economia de escala, a tecnologia patenteada ou o acesso preferencial a matérias-primas. Na diferenciação, a empresa procura alcançar uma posição única na indústria, por meio de atributos que os clientes valorizem e pela disposição desses mesmos clientes a pagar um preço-prêmio pelo produto ou serviço.

Uma abordagem diferente é apresentada por Prahalad e Hamel (1995), enfatizando os fatores internos da organização. Os autores afirmam que a 
Vantagem Competitiva advém das capacidades essenciais da organização, que compreendem o aprendizado coletivo desenvolvido para coordenar as diversas habilidades de produção e integrar as tecnologias. As capacidades essenciais estão associadas à organização, à entrega de valor, à comunicação e ao envolvimento e comprometimento das pessoas. Isto permite à empresa acesso ao mercado, desenvolvimento de produtos cujos benefícios sejam percebidos pelos clientes. Além disto, estas competências essenciais devem ser difíceis de ser imitadas.

Os autores apresentam uma visão estratégica para as organizações, baseada na visão do futuro. Como a empresa pode interagir com este futuro, de forma a garantir que ela tenha espaço privilegiado e pioneiro nas oportunidades do mercado.

Para Prahalad e Hamel (1995), a principal Vantagem Competitiva no futuro seria o desenvolvimento de competências que abram as portas para diversos produtos e mercados. Eles definem como competência essencial o conjunto de habilidades e tecnologias que permite à empresa oferecer determinado benefício ao cliente e consideram que as competências essenciais são as fontes da competitividade, e delas são gerados os produtos e serviços.

Porter (1989) e os dois autores citados acima abordam a Vantagem Competitiva com enfoques diferentes. Enquanto Porter se baseia na estrutura do setor e no posicionamento da empresa no mercado, Prahalad e Hamel enfatizam na sua análise os fatores internos da organização, classificados por eles como competências essenciais e recursos críticos.

As abordagens de Porter e Prahalad e Hamel indicam certo conflito entre as idéias. Entretanto, M. T. L. Fleury e A. Fleury (2001) apresentam uma análise que integra as idéias de estratégia e competência e afirmam que há um círculo virtuoso nas organizações, que se inicia com as estratégias que definem as competências. Estas, por sua vez, influenciam a melhoria das estratégias por meio do processo de aprendizagem organizacional. Da mesma forma, Chandler (1969) aborda as duas dimensões, quando discute a influência da estratégia na estrutura e desta na estratégia.

Aliás, já na década de 60, Chandler (1969) analisou como algumas empresas americanas definiram suas estratégias e como este processo interagiu com as estruturas organizacionais. O autor cita, por exemplo, o caso da DuPont, que reviu sua estratégia de atuação, buscando maior agilidade e descentralização. $\mathrm{O}$ autor analisa como uma estrutura, com menores níveis, aumentou o poder dos gerentes e acabou encorajando-os a tomar decisões sobre novos mercados e produtos, as quais teriam sido muito difíceis de ser tomadas e implementadas na estrutura anterior. É importante destacar que, na época em que Chandler 
desenvolveu tais conceitos, não se utilizava o termo competência organizacional (core competence) como nos dias de hoje.

Ainda acerca do mesmo tema, Porter (1989) entende que é impossível dissociar a posição competitiva das habilidades internas que formam as competências essenciais. Para ele, as atividades da empresa integram suas competências e estratégias, formando a ponte entre os recursos e as capacidades da empresa com sua posição no mercado. Segundo o mesmo autor a habilidade de uma empresa integrar e desenvolver suas atividades é a base da sustentação de suas vantagens competitivas.

Ansoff (1990) aborda o tema vantagem competitiva de forma semelhante aos conceitos defendidos por Porter. $\mathrm{O}$ autor entende que o sucesso da empresa é função da estratégia que ela adota. A estratégia determina a vantagem competitiva da empresa. O autor destaca quatro estratégias competitivas possíveis: (1) Estratégia de participação de mercado, que consiste na otimização da participação de mercado através de uma política de vendas agressiva, baseada em preços baixos e sustentada por custos minimizados; (2) Estratégia de crescimento, que se baseia na expansão territorial do mercado, segmentação do mercado, estimulação da demanda por programas de obsolescência programada, dentre outros; (3) Estratégia de diferenciação do mercado, pela qual a empresa cria uma imagem distinta dos concorrentes e consegue atrair clientes para seus produtos e serviços; (4) Estratégia de diferenciação de produtos e serviços que procura desenvolver produtos diferentes em relação aos da concorrência e que atendam às necessidades específicas de grupos de clientes.

Aaker (2001), Urich e Lake (1990) e Ohmae (1988) também abordam a Vantagem Competitiva em relação a clientes e concorrentes, cada qual enfatizando aspectos diferenciados.

De acordo com Aaker (2001), a vantagem competitiva será criada, se estiver sustentada por ativos, for adotada em segmentos que a valorizem e for empregada contra concorrentes que não poderão facilmente enfrentá-la. Além disto, precisa ser substancial o bastante para fazer a diferença, ser sustentável perante as mudanças no ambiente e na concorrência e estar alinhada com atributos visíveis dos negócios que irão influenciar os clientes.

Para Urich e Lake (1990), a vantagem competitiva ocorre quando a empresa consegue, em segmento específico de mercado, agregar mais valor a seus clientes e fornecedores do que seus concorrentes. A vantagem competitiva se compõe de dois elementos: o valor percebido pelos clientes e a criação de fontes únicas ou singulares através de produtos ou serviços que os concorrentes não conseguem imitar. 
Esses dois autores acreditam que, para competirem com sucesso, as organizações devem construir capacitações organizacionais. Capacitações organizacionais envolvem simultaneamente processos gerenciais e atendimento das demandas dos clientes. Os meios tradicionais para se obter vantagem competitiva que incluíam desenvolvimento de produtos e serviços, com preços menores do que os da concorrência, e o desenvolvimento de tecnologias inovadoras precisam ser complementados por novas capacitações organizacionais.

A Vantagem Competitiva está relacionada ao entendimento correto das necessidades dos clientes (Ohmae, 1988). Segundo o autor, em vez de copiar o que os concorrentes estão fazendo, ou mesmo, antes de ir para a guerra direta contra os concorrentes, a empresa deve analisar o que o cliente realmente quer. Com base nessas informações, é importante colocar toda sua energia e criatividade para desenvolver novas soluções que lhe darão a Vantagem Competitiva Sustentável.

Esta abordagem de Ohmae (1988) é semelhante à apresentada por Prahalad e Hamel (1995) sobre a competência essencial. A diferença é que estes enfatizam a importância de a empresa se antecipar ao futuro, enquanto que Ohmae (1988) destaca o perfeito entendimento das necessidades atuais dos clientes.

Outros autores, como Stalk e Hout (1990), Chandler (1990), e Ghemawat (1986) analisam a Vantagem Competitiva com base em aspectos específicos da organização e do setor. Enquanto Stalk e Hout (1990) e Chandler (1990), por exemplo, destacam a agilidade como Vantagem Competitiva, Ghemawat (1986) aborda situações estruturais da indústria.

Stalk e Hout (1990) entendem que a Vantagem Competitiva depende do bom gerenciamento do tempo na organização, sendo obtida se a empresa conseguir lançar produtos à frente de seus concorrentes e se tiver mais agilidade na produção, nas vendas e na distribuição. Chandler (1990) também destaca, como condição para obter Vantagem Competitiva, a importância de a empresa se antecipar no lançamento de novo produto.

A Vantagem Competitiva Sustentável pode ocorrer em função das seguintes situações: porte do mercado-alvo, quando este proporciona economia de escala, efeitos de experiência e economias de escopo; acesso preferencial a recursos ou a clientes, incluindo know-how, insumos ou mercados; e por opção dos concorrentes mediante política governamental, necessidade de defesa de sua posição ou atraso de resposta (Ghemawat, 1986). Tais fontes de vantagem competitiva também são destacadas por Porter (1989), quando aborda a estratégia de Liderança de Custos. 
Segundo Ghemawat (1986), as vantagens competitivas decorrentes da inovação de produtos, de processos de produção e de estratégias de marketing estão mais difíceis de serem mantidas, porque os concorrentes têm cada vez mais facilidades de as imitarem.

Quanto às vantagens de acesso a recursos ou a clientes, o mesmo autor destaca: o know-how, que pode refletir na escala e na experiência; o acesso privilegiado a insumos importantes; o acesso a mercados de forma preferencial devido à reputação, relacionamentos, custos repassados e a complementaridade de produtos.

Em relação àquelas opções dos concorrentes que podem impedir a imitação da estratégia da empresa, Ghemawat (1999) discute a intervenção do governo no campo das patentes ou das leis antitrustes. Destaca ainda uma política governamental que beneficia quem está do lado correto e impede ou limita outras empresas de se aproveitarem, por exemplo, dos incentivos regionais. Comenta também a situação de defesa, que ocorre quando uma empresa está presa a investimentos feitos no passado, os quais a impedem de dar uma resposta mais agressiva a um novo competidor. Nesta situação, a nova empresa leva uma vantagem e pode tornar-se líder do setor. Por último, menciona os atrasos de resposta, que podem ser fatais para o avanço do concorrente e que normalmente ocorrem com inovações no setor.

Para Ghemawat (1999), a obtenção de uma Vantagem Competitiva depende de se conseguir grande diferença entre o que o cliente quer pagar e os custos que os competidores conseguem ter.

Mais recentemente, com o surgimento da Internet, houve diversas mudanças no comportamento dos consumidores, que passaram a ter mais informações e maior disponibilidade de produtos no mercado (Kotler, 2000). Segundo Kotler, isto mudou a relação de forças e o consumidor passou a ter muito mais poder. Nesse ambiente, alguns autores destacam que a habilidade de as empresas usarem a Internet como instrumento de marketing para atrair seus clientes pode tornarse importante fonte de vantagem competitiva.

Neste novo cenário, surgiu uma abordagem de como o marketing virtual, ou relacionamento através da Internet, pode proporcionar uma vantagem competitiva para a empresa. A natureza da comunicação via Internet pode mudar a forma de contato com o cliente, superando suas expectativas através de respostas rápidas, interatividade e disponibilidade de acesso a qualquer momento e de qualquer lugar do mundo (Johnson \& Busbin, 2000).

Sanderson (1998) destaca que a chave para a empresa desenvolver a vantagem competitiva é como transformar o capital intelectual em ativo intelectual que 
tenha valor para a organização e para os clientes. Para isto é necessário desenvolver metodologias que vinculem o conhecimento com os objetivos e com os fatores críticos de sucesso.

\section{Fontes de Vantagem Competitiva}

As fontes de vantagem competitiva são o resultado das ações estratégicas das empresas (Porter, 1989). Com base nos conceitos apresentados no item anterior sobre Vantagem Competitiva, procurou-se relacionar as fontes de vantagem competitiva indicadas pelos autores estudados.

. Efeitos da experiência - são baseados no porte ao longo do tempo e permitem às empresas estar sempre na dianteira do mercado (Barney, 2002; Ghemawat, 2000).

. Economias de escala - são ganhos decorrentes do volume, que podem ocorrer na produção, na pesquisa, no marketing e na distribuição (Barney, 2002; Chandler, 1990; Ghemawat, 2000; Porter, 1989).

. Economias de escopo - são derivadas de mercados inter-relacionados. Ocorrem quando uma vantagem competitiva sustentável que a empresa detém em um mercado pode ser usada em outro segmento. Depende da capacidade de a empresa partilhar recursos entre as unidades sem alterar o custo (Chandler, 1990; Ghemawat, 2000).

- Marca reconhecida - decorre de investimentos feitos na marca, que levam a uma identificação e preferência dos clientes (Ansoff, 1990; Porter, 1989).

. Produto diferenciado - é obtido por meio do lançamento de produtos diferentes daqueles oferecidos pela concorrência, que atendem a demandas específicas de segmentos de clientes (Ansoff, 1990; Barney, 2002; Porter, 1989).

- Necessidade de capital. Ocorre quando são necessários altos investimentos para entrar no negócio, protegendo e privilegiando a empresa que detinha o capital e já fez os investimentos (Porter, 1989).

- Acesso privilegiado a canais de distribuição - ocorre quando novos concorrentes têm dificuldade para entrar no canal de distribuição tradicional (Porter, 1989).

- Desvantagens de custos independentes do porte - são vantagens que podem vir de acesso privilegiado a matérias-primas, de tecnologia proprietária, de subsídios, de localização favorável ou de ativos adquiridos em condições mais favoráveis no passado (Porter, 1989). 
- Política governamental - existe quando a empresa é protegida por limitações legais em função de problemas ambientais, uso de matérias-primas da natureza, requisitos de licenças ou de segurança (Porter, 1989).

- Know-how - tecnologia desenvolvida pela empresa, que pode ser mantida em segredo ou protegida (Ghemawat, 2000; Porter, 1989).

Acesso a insumos - ocorre quando o fornecimento é limitado; a empresa possui o direito de uso, ou quando é conseguido por integração vertical (Barney, 2002; Ghemawat, 2000; Porter, 1989).

Acesso a mercados - baseia-se em mecanismos que por si se impõem: reputação, relacionamento, custos agrupados e complementaridade de produtos (Ghemawat, 2000).

. Opção de defesa - existe quando o concorrente está restrito por investimentos feitos no passado, os quais precisam ser protegidos (Ghemawat, 2000).

- Competência essencial para inovação - ocorre quando a empresa, através da inovação, desenvolve uma capacidade para embutir nos produtos uma funcionalidade irresistível (Prahalad \& Hamel, 1995).

- Competência essencial para criar novos produtos - ocorre quando a empresa desenvolve uma competência para criar produtos de que os clientes necessitam, mas não imaginam (Prahalad \& Hamel, 1990).

- 'Caráter' da organização - as empresas podem desenvolver uma capacidade distintiva e desta forma obter uma vantagem competitiva por meio da personificação dos valores na estrutura (Selznick, 1971).

- Compreensão da real necessidade do cliente - é decorrente da estratégia de estudar profundamente seus gostos e necessidades. Com base nisto, é possível desenvolver o produto adequado. Não seguir os concorrentes apenas; mas, se possível, estar à frente; ganhar a batalha sem o confronto (Ohmae, 1988).

- Tecnologia de serviços - é alcançada quando a empresa concentra suas energias em atividades que possam criar valor único para os clientes, naquelas que ela precisa controlar para manter sua supremacia nos elementos críticos de sua cadeia de valores. Devido ao presente nivelamento da produção (tudo está ficando muito parecido no mercado), a empresa deve identificar as poucas atividades de serviços que significarão sua capacitação única, e deve terceirizar o resto (Quinn, Doorley, \& Paquete, 1990).

Alianças logísticas - obtidas por meio de alianças que podem reduzir custos 
de distribuição e levar a uma melhoria dos serviços aos clientes (Bowersox, 1990).

- Desenvolvimento da logística do empreendimento gerencial - é conseguida se a empresa investir antes de seus concorrentes, de forma estruturada, para gerar economias de escala, economias de escopo, fluxos de produção constantes, criar organizações de marketing e recrutar e manter o corpo gerencial (Chandler, 1990).

- Capacidade geral de fabricação superior - é decorrente da capacidade de fabricação superior que inclui tecnologias, credibilidade, influência para a produção, ênfase nas atividades estruturais e planejamento a longo prazo (Wheelwright \& Hayes, 1985).

- Capital intelectual - resulta do gerenciamento das atividades de conhecimento de modo a aumentar o valor dos produtos e serviços para os clientes (Mouritsen, Bukl, Larcen, \& Johansen, 2002; Sanderson, 1998).

- Tempo-ocorre por meio do gerenciamento do tempo para melhorar os processos da empresa, a produção, de modo a reduzir o tempo de lançamento de novos produtos, para a gestão das vendas e da distribuição (Stalk \& Hout, 1990).

- Marketing virtual - surge a partir da gestão adequada do relacionamento com os clientes através da Internet (Johnson \& Busbin, 2000).

- Integração vertical - é decorrente do número de atividades que a empresa desenvolve, vinculadas diretamente à sua cadeia de produto ou serviço; quanto maior esse número, maior o nível de integração. A vantagem competitiva ocorre quando é possível obter custos agregados menores e quando a empresa fica menos vulnerável em face de comportamentos oportunistas que possam ocorrer nos seus processos de produção e comercialização (Barney, 2002).

- Flexibilidade - é decorrente da possibilidade de a empresa crescer, reduzir, fechar ou reiniciar suas atividades em função de oportunidades ou ameaças no ambiente competitivo (Barney, 2002).

\section{Vantagem Competitiva Sustentável}

A Vantagem Competitiva se refere à posição da empresa em relação aos clientes e concorrentes. Ela pode ou não ser sustentável, isto é, ser duradoura e resistir aos ataques da concorrência.

Barney (1995) e Porter (1989) desenvolveram critérios para avaliar a sustentabilidade das vantagens competitivas, os quais estão comentados a seguir. 
Há, segundo Barney (1995), quatro critérios para julgar se os recursos e capacitações da empresa geram fontes de vantagem competitiva sustentável: (1) Valor - os recursos e capacitações agregam valores que permitem explorar as oportunidades e neutralizar as ameaças; (2) Raridade - Os recursos e capacitações são exclusivos da empresa ou outros competidores também possuem. Para ser raro, é preciso ser exclusivo da empresa, pelo menos por algum tempo; (3) Imitação - Se o custo ou investimento com que o concorrente tiver que arcar para obter o recurso ou capacitação for alto ou desvantajoso, então será uma VCS; (4) Organização - A organização da empresa, formada pelos seus sistemas de controle, de informações e das suas políticas de compensação, permite que ela explore estrategicamente o potencial de seus recursos e capacitações. A criação de vantagens competitivas sustentáveis depende da forma única que seus recursos e capacitações se combinam para que a empresa atue no mercado. Recursos e capacitações incluem os recursos financeiros, físicos, humanos e os ativos da organização usados para desenvolver produtos e serviços para os clientes da empresa.

Para Porter (1989), a sustentabilidade de uma vantagem competitiva dependerá da sua resistência ao comportamento da concorrência e à evolução da indústria (setor). Para isto, a empresa deve desenvolver barreiras que dificultem a imitação da sua estratégia, mediante investimentos permanentes na melhoria de sua posição, de forma que ela se torne um alvo móvel e difícil de ser copiado.

\section{Procedimentos Metodológicos}

Para a avaliação dos objetivos propostos realizou-se um estudo exploratório com base em uma amostra probabilística composta de 624 indivíduos que apresentou um nível de significância de $90 \%$. Utilizou-se um processo amostral sistemático, mediante a seleção dos entrevistados ao longo dos dias úteis do mês de Novembro de 2004, distribuídos entre os períodos matutinos e vespertinos, seguindo a mesma distribuição observada no Hospital Cema onde foi feita a pesquisa. O universo compreendeu o contingente populacional das pessoas residentes na zona sudeste do município de São Paulo, que possui plano de saúde e que tenha usado os serviços do hospital Cema durante os meses de outubro e novembro de 2004. Vale destacar que este hospital tem $90 \%$ de participação no mercado da região sudeste nas especialidades de otorrinolaringologia e oftalmologia.

Optou-se pelos portadores de planos de saúde de pessoa física, que representam 
30\% do mercado, conforme dados da Agência Nacional de Saúde (2004), uma vez que a decisão de escolha da marca do plano depende exclusivamente do próprio usuário. Os outros $70 \%$ do mercado compreendem os planos corporativos, cuja decisão de compra é feita pela empresa.

Para a coleta de informações foi utilizado um questionário estruturado. Foram definidas 16 questões relacionadas às 14 fontes de vantagem competitiva citadas no referencial teórico. As perguntas foram desenvolvidas para ser entendidas pelos entrevistados de forma simples, uma vez que a maioria pertence às classes B e C $(98,5 \%)$. Ao mesmo tempo indicam uma relação entre a preferência pelo cliente e a fonte de vantagem competitiva que preconiza a opção feita por determinada marca. Por exemplo, as perguntas 1 e 16 indicam que a escolha da empresa foi feita em função do custo do plano. No caso de o entrevistado ter escolhido o plano em função destas variáveis, entende-se que a empresa consegue os custos competitivos mediante as fontes de vantagem competitivas citadas de 1 a 5 no referencial teórico como sendo a sustentação da estratégia de liderança de custos, também indicados no Quadro 1.

\section{Quadro 1: Conexão entre as Fontes de Vantagem Competitiva e o Questionário}

\begin{tabular}{|c|c|}
\hline FONTE DE VANTAGEM COMPETITIVA & PERGUNTA \\
\hline $\begin{array}{l}\text { Fontes citadas no referencial teórico que permitem à empresa custos } \\
\text { mais baixos em seu setor: } \\
1 \text { - Economia de Escala, Tecnologia patenteada, Acesso preferencial a } \\
\text { matérias-primas (Ansoff, 1990; Porter, 1989). Fontes que sustentam a } \\
\text { estratégia de Liderança de Custos, que permite à empresa ter o menor } \\
\text { custo do setor. } \\
\text { 2- Economia de Escopo (Chandler, 1990; Ghemawat, 2000); } \\
3 \text { - Acesso a insumos (Ghemawat, 2000; Porter, 1989); } \\
4 \text { - Alianças logísticas (Bowersox, 1990). } \\
5 \text { - Desvantagens de custo, independentemente do porte (Porter, 1989). }\end{array}$ & $\begin{array}{l}1 \text { - Minha decisão de escolha do plano de saúde se } \\
\text { baseou exclusivamente no preço. } \\
16 \text { - O custo do plano de saúde é compatível com } \\
\text { os benefícios que me proporciona. }\end{array}$ \\
\hline $\begin{array}{l}\text { Fontes que sustentam a estratégia de diferenciação: } \\
6 \text { - Marca reconhecida e atributos de produtos (Ansoff, 1990; Porter, } \\
\text { 1989). }\end{array}$ & $\begin{array}{l}3 \text { - A qualidade diferenciada da rede de médicos, } \\
\text { clínicas e hospitais é o fator mais importante para a } \\
\text { escolha do plano de saúde. } \\
4 \text { - A marca da empresa é o fator mais importante } \\
\text { na escolha do plano de saúde. } \\
9 \text { - Entre duas empresas com produtos equivalentes } \\
\text { prefiro a empresa que tiver a marca mais conhecida, } \\
\text { mesmo que o preço seja um pouco mais elevado. }\end{array}$ \\
\hline
\end{tabular}




\section{(conclusão)}

\section{Quadro 1: Conexão entre as Fontes de Vantagem Competitiva e o Questionário}

\begin{tabular}{|c|c|}
\hline FONTE DE VANTAGEM COMPETITIVA & PERGUNTA \\
\hline $\begin{array}{l}\text { Fontes que permitem à empresa ser inovadora: } \\
7 \text { - Competência essencial para inovação (Prahalad \& Hamel, 1995). } \\
8 \text { - Capital intelectual (Mouritsen et al., 2002; Sanderson, 1998) }\end{array}$ & $\begin{array}{l}6 \text { - Escolho a empresa que lança novos produtos. } \\
11 \text { - O pioneirismo, lançar novidades sempre na } \\
\text { frente dos concorrentes, é muito importante para a } \\
\text { escolha da empresa de plano de saúde. }\end{array}$ \\
\hline $\begin{array}{l}\text { Entender a necessidade do cliente } \\
9 \text { - Entender a real necessidade do cliente e desenvolver produtos } \\
\text { adequados (Ohmae, 1988). }\end{array}$ & $\begin{array}{l}10 \text { - Ter um canal de comunicação fácil para } \\
\text { discutir meus problemas e necessidades em relação } \\
\text { ao plano de saúde é o que me interessa. } \\
12 \text { - Dou preferência para a empresa que é } \\
\text { interessada em conhecer minhas necessidades. }\end{array}$ \\
\hline $\begin{array}{l}\text { Ter processos mais ágeis do que os concorrentes: } \\
10 \text { - Gerenciamento adequado do tempo para melhorar processos, } \\
\text { produtos, produção, reduzir o tempo de lançamento de novos produtos, } \\
\text { e para gestão das vendas e da distribuição (Stalk e Hout, 1990). }\end{array}$ & $\begin{array}{l}8 \text { - Reembolso rápido e agilidade na emissão de } \\
\text { guias são aspectos decisivos na escolha do plano de } \\
\text { saúde. } \\
13 \text { - A agilidade no atendimento é muito } \\
\text { importante na escolha do plano de saúde. }\end{array}$ \\
\hline $\begin{array}{l}\text { Ter recursos para altos níveis de investimentos: } \\
11 \text { - Necessidade de capital que ocorre quando são necessários altos } \\
\text { investimentos para entrar no negócio, que protege a empresa que } \\
\text { detinha o capital e já fez o investimento (Porter, 1989). }\end{array}$ & $\begin{array}{l}14 \text { - O tamanho (porte) da empresa é importante } \\
\text { para a escolha do plano de saúde. }\end{array}$ \\
\hline $\begin{array}{l}\text { Ter acesso privilegiado ao canal de distribuição } \\
12 \text { - Acesso privilegiado ao canal de distribuição que ocorre quando os } \\
\text { concorrentes têm dificuldade para entrar no canal de distribuição } \\
\text { tradicional. (Porter, 1989). }\end{array}$ & $\begin{array}{l}15 \text { - Meu corretor influencia decisivamente na } \\
\text { minha escolha do plano de saúde. }\end{array}$ \\
\hline $\begin{array}{l}\text { Ter estrutura de relacionamento pela Internet: } \\
\text { 13- Marketing virtual - surge a partir da gestão adequada do } \\
\text { relacionamento com os clientes por meio da Internet (Johonson \& } \\
\text { Busbin, 2000) }\end{array}$ & $\begin{array}{l}\text { 2- Dou preferência ao convênio que resolve meus } \\
\text { problemas pela Internet. } \\
\text { 7- Gosto de me relacionar com o convênio pela } \\
\text { Internet. }\end{array}$ \\
\hline $\begin{array}{l}\text { Ter capacitação tecnológica: } \\
14 \text { - Know-how - Tecnologia desenvolvida pela empresa que pode ser } \\
\text { mantida em segredo ou protegida. (Ghemawat, 2000; Porter, 1989). }\end{array}$ & $\begin{array}{l}5 \text { - Escolho a empresa de saúde que possuir } \\
\text { tecnologia mais avançada. }\end{array}$ \\
\hline
\end{tabular}

Fonte: Autores do projeto.

Para avaliação dos resultados foram utilizadas técnicas estatísticas descritivas e a análise fatorial baseada nos componentes principais. A utilização desta técnica deveu-se ao fato de o método da análise fatorial, baseada na máxima verossimilhança, necessitar da suposição da normalidade multivariada dos dados que, no caso desta pesquisa, não se sustenta, tendo em vista a escala do tipo 
Likert adotada no questionário (Hair, Anderson, Tathan, \& Black, 1995, 1998; Johnson \& Wichem, 1998).

\section{Resultados e Discussão}

As estatísticas descritivas mais importantes indicaram que a idade média dos entrevistados foi de 41,6 anos, que está acima da média da população coberta por planos de saúde no Brasil, que é 32,2 anos conforme dados da ANS. Quanto ao sexo dos entrevistados, $43,3 \%$ são homens e $56,7 \%$ mulheres, muito próximos da população indicada pela ANS.

Em relação ao grau de instrução, verificou-se que $27,8 \%$ não completaram o ensino básico, 45,5\% têm o colegial ou o superior incompleto e $25,6 \%$ têm o superior completo. Sobre classe socioeconômica, 74,3\% pertencem à classe B, $24,2 \%$ à $\mathrm{C}, 1 \%$ à $\mathrm{D}$ e $1,4 \%$ à $\mathrm{A}$. Comparando-se com os dados o IBGE, nota-se que a amostra indica que os usuários de planos de saúde da zona sudeste apresentam perfil socioeconômico superior à média da população brasileira.

Destacam-se ainda o tempo médio, que possui o plano 31,2 meses, o valor médio da mensalidade $\mathrm{R} \$ 313,90$ e o número médio de dependentes 0,51 .

A análise do objetivo principal, identificar quais fontes de vantagem competitiva, na opinião dos clientes, influenciam mais sua decisão de escolha da marca da operadora de planos de saúde, foi feita por meio da técnica de análise fatorial, técnica que agrupa as diversas variáveis pesquisadas. $\mathrm{O}$ KMO - Kaiser-Meyer-Olkin- foi 0,833; e o teste de Bartlett resultou em $2.932,93(\mathrm{p}<0,001)$, indicando que a realização da Análise Fatorial foi adequada. O coeficiente alfa de Cronbach foi de 74,25\%, o que demonstra boa coerência das respostas apresentadas. Índices acima de $60 \%$ são considerados satisfatórios (Hair et al., 1995; Malhotra, 2001).

Desta forma, visando alcançar um grau de explicação mínima de $70 \%$ da variabilidade total das variáveis originais, optou-se pela utilização dos seis primeiros fatores, conforme demonstrado na Tabela 1. A utilização do critério de pelo menos $70 \%$ da variabilidade explicada, em detrimento do método da raiz latente, deveuse ao fato de tal critério ter apresentado um total de apenas três fatores responsáveis por $54,18 \%$ da variabilidade total, corroborando a afirmação de Hair de que o método da raiz latente tende a subestimar o número de fatores nos casos em que o número de variáveis é inferior a 20 (Hair et al., 1995). 


\section{Tabela 1: Análise Fatorial das Fontes de Vantagem Competitivas - Extração dos Fatores}

\begin{tabular}{|c|c|c|c|c|c|c|c|c|c|}
\hline \multirow[b]{2}{*}{ Component } & \multicolumn{3}{|c|}{ Initial Eigenvalues } & \multicolumn{3}{|c|}{ Extraction Sums of Squared Loadings } & \multicolumn{3}{|c|}{ Rotation Sums of Squared Loadings } \\
\hline & Total & $\%$ of Variance & Cumulative \% & Total & $\%$ of Variance & Cumulative $\%$ & Total & $\%$ of Variance & Cumulative \% \\
\hline 1 & 3,778 & 25,186 & 25,186 & 3,778 & 25,186 & 25,186 & 3,118 & 20,787 & 20,787 \\
\hline 2 & 3,288 & 21,918 & 47,103 & 3,288 & 21,918 & 47,103 & 2,148 & 14,320 & 35,107 \\
\hline 3 & 1,062 & 7,081 & 54,184 & 1,062 & 7,081 & 54,184 & 1,711 & 11,409 & 46,516 \\
\hline 4 & ,942 & 6,277 & 60,461 & ,942 & 6,277 & 60,461 & 1,706 & 11,374 & 57,890 \\
\hline 5 & ,857 & 5,713 & 66,174 & ,857 & 5,713 & 66,174 & 1,028 & 6,857 & 64,746 \\
\hline 6 & ,796 & 5,309 & 71,483 & ,796 & 5,309 & 71,483 & 1,011 & 6,737 & 71,483 \\
\hline 7 & ,712 & 4,745 & 76,228 & & & & & & \\
\hline 8 & ,655 & 4,367 & 80,595 & & & & & & \\
\hline 9 &, 520 & 3,467 & 84,063 & & & & & & \\
\hline 10 & ,496 & 3,306 & 87,368 & & & & & & \\
\hline 11 & ,474 & 3,157 & 90,525 & & & & & & \\
\hline 12 & ,425 & 2,831 & 93,356 & & & & & & \\
\hline 13 & ,401 & 2,674 & 96,030 & & & & & & \\
\hline 14 & ,350 & 2,333 & 98,363 & & & & & & \\
\hline 15 & ,246 & 1,637 & 100,000 & & & & & & \\
\hline
\end{tabular}

Fonte: Pesquisa dos Autores - Base de Dados: SPSS - Versão 11.0.

A Tabela 2, matriz de cargas fatoriais rotacionadas segundo o método Varimax, visa auxiliar a interpretação de cada um dos fatores. Estão destacados os valores de correlação mais elevados entre cada variável original e os fatores selecionados.

\section{Tabela 2: Análise Fatorial das Fontes de Vantagem Competitiva - Cargas Fatoriais}

Rotated Component Matrix ${ }^{\text {a }}$

\begin{tabular}{|c|c|c|c|c|c|c|}
\hline & \multicolumn{6}{|c|}{ Component } \\
\hline & 1 & 2 & 3 & 4 & 5 & 6 \\
\hline $\begin{array}{l}\text { Conhecimento das } \\
\text { necessidades dos } \\
\text { clientes }\end{array}$ & ,794 &,- 097 &, 070 &,- 052 & ,196 &,- 060 \\
\hline $\begin{array}{l}\text { Escolha pela rede } \\
\text { conveniada }\end{array}$ & ,786 &,- 080 &, 210 &,- 011 &, 178 &,- 008 \\
\hline $\begin{array}{l}\text { Canal de comunicação } \\
\text { fácil }\end{array}$ & ,780 &, 145 &,- 084 &,- 033 &,- 127 &,- 026 \\
\hline $\begin{array}{l}\text { Reembolso rápido e } \\
\text { agilidade na guia }\end{array}$ & ,751 &, 173 &,- 210 &, 060 &,- 065 &,- 029 \\
\hline $\begin{array}{l}\text { Escolha baseada na } \\
\text { Agilidade }\end{array}$ & ,730 &,- 048 &,- 016 &,- 096 &, 214 &,- 068 \\
\hline $\begin{array}{l}\text { Preferência pela marca } \\
\text { mais conhecida }\end{array}$ & ,169 & ,739 &, 145 & ,167 &,- 250 &, 000 \\
\hline Pioneirismo & ,092 & ,662 &,- 039 &, 252 &, 210 &,- 045 \\
\hline Porte da empresa &,- 119 & ,631 & ,342 &, 110 &, 148 &, 050 \\
\hline $\begin{array}{l}\text { Escolha pela Marca da } \\
\text { empresa }\end{array}$ &,- 142 & ,596 &, 520 &, 152 &, 051 & ,025 \\
\hline $\begin{array}{l}\text { Possui tecnologia } \\
\text { mais avançada }\end{array}$ &, 010 &, 100 & ,841 & ,204 &,- 001 &,- 064 \\
\hline
\end{tabular}




\section{(conclusão)}

\section{Tabela 2: Análise Fatorial das Fontes de Vantagem Competitiva - Cargas Fatoriais}

\begin{tabular}{|c|c|c|c|c|c|c|}
\hline & \multicolumn{6}{|c|}{ Component } \\
\hline & 1 & 2 & 3 & 4 & 5 & 6 \\
\hline Lança novos produtos &, 050 & 431 & ,634 & ,208 &, 053 & ,095 \\
\hline $\begin{array}{l}\text { Resolve problemas } \\
\text { pela internet }\end{array}$ &,- 089 & ,206 &, 205 & ,868 &, 001 &, 101 \\
\hline $\begin{array}{l}\text { Relacionamento via } \\
\text { internet }\end{array}$ &,- 035 &, 302 & ,216 & ,849 &,- 020 &,- 025 \\
\hline $\begin{array}{l}\text { Custo compatível com } \\
\text { benefícios }\end{array}$ &, 264 &, 111 &, 052 &,- 006 & ,870 &,- 037 \\
\hline $\begin{array}{l}\text { Escolha baseada no } \\
\text { preço }\end{array}$ &,- 116 &, 010 &,- 002 &, 058 &,- 037 & ,985 \\
\hline
\end{tabular}

Extraction Method: Principal Component Analysis.

Rotation Method: Varimax with Kaiser Normalization.

a. Rotation converged in 7 iterations.

Fonte: Pesquisa dos Autores - Base de Dados: SPSS - Versão 11.0.

Com o objetivo de avaliar a validade da análise fatorial, foi feita uma divisão da amostra em duas partes (Hair et al., 1995), por meio da qual se pôde constatar a estabilidade dos fatores, conforme demonstra a Tabela 3 referente às cargas fatoriais de uma amostra de $50 \%$ das entrevistas realizadas:

\section{Tabela 3: Cargas Fatoriais de 50\% das Entrevistas Realizadas}

\begin{tabular}{|lrrrrrr|}
\hline & & & & & & \\
Conhecimento das necessidades dos clientes & 1 & 2 & 3 & 4 & 5 & 6 \\
Escolha pela rede conveniada & $\mathbf{0 , 7 8 0}$ & $-0,122$ & 0,027 & 0,015 & 0,260 & $-0,078$ \\
Canal de comunicação fácil & $\mathbf{0 , 7 7 2}$ & $-0,041$ & 0,288 & $-0,056$ & 0,180 & 0,039 \\
Reembolso rápido e agilidade na guia & $\mathbf{0 , 7 3 7}$ & 0,187 & $-0,026$ & $-0,164$ & $-0,205$ & $-0,131$ \\
Escolha baseada na Agilidade & $\mathbf{0 , 7 4 3}$ & 0,233 & $-0,218$ & $-0,041$ & $-0,135$ & $-0,040$ \\
Preferência pela marca mais conhecida & $\mathbf{0 , 7 3 5}$ & $-0,108$ & $-0,084$ & 0,044 & 0,313 & $-0,051$ \\
Pioneirismo & 0,201 & $\mathbf{0 , 7 6 4}$ & 0,050 & 0,079 & $-0,233$ & 0,003 \\
Porte da empresa & 0,083 & $\mathbf{0 , 7 0 8}$ & $-0,040$ & 0,280 & 0,104 & 0,037 \\
Escolha pela Marca da empresa & 0,078 & $\mathbf{0 , 6 4 7}$ & 0,260 & 0,086 & 0,258 & $-0,072$ \\
Possui tecnologia mais avançada & 0,157 & $\mathbf{0 , 6 7 5}$ & 0,334 & 0,219 & 0,055 & $-0,007$ \\
Lança novos produtos & 0,011 & 0,204 & $\mathbf{0 , 8 5 8}$ & 0,245 & $-0,012$ & $-0,022$ \\
Resolve problemas pela internet & 0,044 & 0,533 & $\mathbf{0 , 5 6 8}$ & 0,172 & 0,039 & 0,131 \\
Relacionamento via internet & 0,096 & 0,197 & 0,193 & $\mathbf{0 , 8 6 7}$ & $-0,009$ & 0,088 \\
Custo compatível com benefícios & 0,038 & 0,357 & 0,170 & $\mathbf{0 , 8 0 5}$ & $-0,123$ & 0,017 \\
Escolha baseada no preço & 0,240 & 0,129 & 0,017 & $-0,106$ & $\mathbf{0 , 8 4 7}$ & $-0,056$ \\
& 0,150 & 0,007 & 0,025 & 0,082 & $-0,058$ & $\mathbf{0 , 9 7 3}$ \\
\hline
\end{tabular}

Fonte: Pesquisa dos Autores. Base de Dados: SPSS - Versão 11.0.

Portanto, a partir da Tabela 2, foram nomeados fatores, levando em conta as perguntas feitas e sua conexão com as fontes de vantagem competitivas citadas 
no referencial teórico. Conforme sua ordem de importância para os clientes, os fatores identificados foram os seguintes.

Fator 1: Agilidade e Atendimento, que engloba a qualidade da rede assistencial, o conhecimento das necessidades dos clientes, a rapidez na solução dos problemas e o canal de comunicação, conforme se indica na Tabela 2.

Considerando-se o referencial teórico, verifica-se que as variáveis sumariadas no fator 1 englobam os atributos do produto citados por Porter (1989) como uma das fontes da estratégia de diferenciação; o entendimento da real necessidade do cliente e o desenvolvimento de produtos adequados, citados por Ohmae (1988); e o gerenciamento adequado do tempo para melhorar os processos indicados por Stalk e Hout (1990). O conhecimento das necessidades dos clientes e a escolha da rede assistencial foram denominadas de Atendimento. O canal de comunicação fácil, o reembolso rápido, agilidade na emissão das guias e a escolha baseada na agilidade foram denominados Agilidade.

Fator 2: Marca, Pioneirismo e Porte referem-se à empresa que está por trás do plano de saúde. Neste caso o referencial teórico inclui a marca citada por Porter (1989) como fonte de vantagem competitiva para a estratégia de diferenciação; a competência essencial para inovação (pioneirismo) destacada por Prahalad e Hamel (1995) e a necessidade de capital (porte da empresa) também citada por Porter (1989) como fonte de vantagem competitiva.

Fatores 3: Preço. Consideraram-se os fatores 5 e 6 indicados na Tabela 1, uma vez que se referem a duas dimensões da mesma variável Preço, possibilitando que a empresa ofereça aos clientes uma boa relação custo benefício ou um preço competitivo. É decorrente de estratégias que sustentam esta fonte de vantagem competitiva. Dentre as fontes de vantagem competitiva relativas ao custo os autores destacam: economia de escala, tecnologia patenteada e acesso preferencial a matérias-primas (Barney, 2002; Porter, 1989); economia de escopo (Chandler, 1990; Ghemawat, 2000); acesso a insumos (Barney, 2002; Ghemawat, 2000); alianças logísticas (Bowersox 1990); e desvantagens de custo independentemente do porte (Porter, 1989).

Fator 4: Inovação, que inclui a competência para modificar e criar novos produtos. Neste fator estão incluídos como fontes de vantagem competitiva o know-how destacado por Ghemawat (2000) e Porter (1989); e a competência essencial para inovação, relacionada por Prahalad e Hamel (1995).

Fator 5: Internet refere-se à condição de a empresa resolver os problemas dos clientes pela Internet e de se relacionar pela Internet. No referencial teórico estas fontes de vantagem competitiva estão agrupadas no marketing virtual, como 
destacado por Johnson e Busbin (2000), quando se referem à adequada gestão do relacionamento com os clientes através da Internet.

\section{CONCLUSÕES}

Dentre os conceitos de estratégia citados no referencial teórico, foram consideradas neste estudo as abordagens das escolas clássica e sistêmica (Whittington, 2002), assim como a definição de Porter (1989). Os defensores da escola clássica entendem que o problema estratégico fundamental deve ser a posição da empresa no mercado que lhe garanta os maiores índices de lucratividade. Para a escola sistêmica, as estratégias refletem os sistemas sociais em que a empresa se insere e suas mudanças. Segundo Porter, a estratégia compreende a definição de um posicionamento para a empresa baseado em vantagens competitivas, que seja lucrativo e ao mesmo tempo sustentável contra $\mathrm{o}$ ataque dos concorrentes.

No caso do setor de planos de saúde, objeto deste estudo, desde a mudança na legislação ocorrida em 1998, as empresas estão tendo de se adaptar ao novo cenário competitivo para sobreviver, como conceitua a escola sistêmica. Por outro lado, elas precisam rever seu posicionamento no mercado visando manter e aumentar sua participação, de forma lucrativa e duradoura, como defendem os autores clássicos e Porter (1989).

Como foi destacado no referencial teórico, um dos objetivos da estratégia empresarial é desenvolver vantagem competitiva para a empresa. Esta vantagem, do ponto de vista do cliente, deve ter um valor que supere seu custo. Além disto, deve ser rara, difícil de ser imitada e duradoura (Barney, 1995; Porter, 1989).

Os fatores indicados na análise fatorial também destacaram como fontes mais importantes a rede assistencial, a agilidade, o conhecimento das necessidades dos clientes e a comunicação, conforme demonstrado abaixo. A Agilidade e Atendimento compreendem rede assistencial, conhecimento das necessidades dos clientes, comunicação e agilidade na emissão de guias e no reembolso, que representaram 25,2\% da variabilidade total. Marca, pioneirismo e porte representaram 21,9\%; Preço 11,0\%; Inovação 7,1\% e Internet 6,3\%.

Com base na análise fatorial, as conclusões indicam que os consumidores valorizam em primeiro lugar os aspectos intrínsecos do serviço de saúde que foram destacados no primeiro fator. Incluem a rede assistencial formada pelos hospitais, consultórios e laboratórios que prestam assistência médica, a agilidade 
com que a operadora autoriza os procedimentos por meio da liberação das guias e o tempo do reembolso das despesas, a preocupação com as necessidades dos clientes e a forma de comunicação. Esta constatação é muito importante para as operadoras, uma vez que destaca que antes da marca e do preço, no caso de serviços de saúde, os consumidores estão muito mais preocupados com a qualidade da rede assistencial e com a agilidade para emissão de guias e reembolso.

A marca, o pioneirismo e o porte da operadora, ou seja, a realidade da empresa prestadora de serviços, em termos de tradição e tamanho, também é importante, conforme indicado pelo segundo fator que explicou $21,9 \%$ da variabilidade das respostas.

O fator preço, que vem sendo um dos principais focos de marketing dos competidores, aparece em terceiro lugar entre os fatores destacados pelos usuários, explicando 11,0\% da variabilidade total observada. Embora surpreendente, vale destacar que o preço médio do plano informado foi de $\mathrm{R} \$ 313,90$ que, ajustado pela média de 1,51 pessoas cobertas, resulta em $\mathrm{R} \$ 210$ por pessoa. A população indicada na amostra, basicamente de classe média, para a qual a saúde é um fator crítico de preocupação, o valor foi considerado razoável, ou seja, não representa um problema.

O que vem se discutindo muito na mídia, objeto de reclamações dos usuários, reclamações apuradas pela ANS, não se refere ao preço do plano, mas aos aumentos propostos e às exclusões nas coberturas básicas.

Esses aspectos podem dar subsídios às operadoras nesta nova fase do mercado. Ao mesmo tempo que precisam adaptar-se às mudanças que vêm sendo implementadas pela ANS, eventuais ajustes nas suas estratégias competitivas podem reforçar suas posições no mercado, de forma a ajudar na busca pela preferência dos consumidores.

\section{Limitações, Hipóteses e Recomendações para Estudos Futuros}

As conclusões desta pesquisa se referem aos usuários, pessoas físicas, que possuem planos de saúde, que residem na zona leste e que utilizaram o hospital Cema nos meses de outubro e novembro de 2003. Embora o hospital Cema possua $90 \%$ de participação de mercado nesta região, as conclusões não podem ser generalizadas para todo o município.

Outro aspecto importante a considerar foi a dificuldade de se transformarem as diversas estratégias competitivas discutidas no referencial teórico em questões 
que fossem acessíveis aos consumidores. Mediante o uso de frases assertivas, baseadas numa escala do tipo Likert, procurou-se facilitar o entendimento das questões relacionadas.

O teste de validade discriminante não pôde ser feito, uma vez que ele exigiria a existência de medidas que pudessem exprimir os fatores construídos, ou seja: para a validação da análise fatorial dever-se-ia ter uma forma de medir a agilidade do atendimento, por exemplo avaliando o tempo de espera de cada empresa; da mesma forma aferir o poder da marca, o grau de inovação e assim por diante, o que no presente estudo era completamente inviável.

Em relação a estudos futuros, recomenda-se a avaliação das estratégias competitivas junto aos clientes corporativos. Conforme destacado, este estudo se restringiu aos usuários de planos de pessoas físicas, que correspondem a 30\% do total, conforme dados da ANS. O segmento de planos empresariais ou corporativos representa os outros $70 \%$. Neste caso a pesquisa seria direcionada aos gerentes ou diretores de recursos humanos, ou financeiros que são as pessoas que normalmente selecionam as empresas prestadoras de assistência médica.

Dever-se-ia avaliar melhor a importância dada ao relacionamento pela Internet, uma vez que a maioria dos entrevistados é das classes $\mathrm{C} \mathrm{e} \mathrm{B}$, cujo acesso à Internet é limitado. Pode ter ocorrido um viés devido aos fatores aspiracionais das pessoas que em determinadas situações citam preferências apenas por questões sociais.

\section{Artigo recebido em 28.01.2005. Aprovado em 03.08.2005.}

\section{RefERÊNCIAS BibliográficAS}

Aaker, D. A. (2001).

Administração estratégica de mercado. Porto Alegre: Bookman.

Agência Nacional de Saúde (2004).

Caderno de informações da saúde suplementar - operadoras de planos de saúde Recuperado em 30 março, 2004, de http://ans.org.br/portal/site/ infomacoesss/informacoesss.asp

Ansoff, H. I. (1990).

A nova estratégia empresarial. São Paulo: Atlas.
Barney, J. B. (1995).

Looking inside for the competitive. The Academy of Management Executive. 9(4), 49-61. Recuperado em 20 setembro, 2002, de http:// proquest.umi.com/pqdweb?index = $6 \&$ did $=8082726 \&$ SrchMode $=1 \&$ sid $=$ $3 \& \mathrm{Fmt}=3 \& \mathrm{VInst}=\mathrm{PROD} \& \mathrm{VType}=$ $\mathrm{PQD} \& \mathrm{RQT}=309 \& \mathrm{VName}=\mathrm{PQD} \& \mathrm{TS}=$ $1195505747 \&$ clientId=18113

Barney, J. B. (2002).

Gaining and sustaining competitive advantage. New Jersey: Education Inc. 
Bowersox, D. J. (1990).

The strategic benefits of logistics alliances. Harvard Business Review 68(4), 36-42.

Chandler, A. K. (1969).

Strategy and structure: chapters in the history of the american industrial enterprise. Massachusetts: Library of Congress Cataloguing-in- Publication.

Chandler, A. K. (1990).

The enduring logic of industrial success. Harvard Business Review 68(2), 130-141.

Fleury, M. T. L., \&

Fleury, A. (2001).

Estratégias empresariais e formação de competências: um quebra-cabeça caleidoscópico da indústria brasileira. São Paulo: Atlas.

Ghemawat, P. (1986).

Sustainable advantage. Harvard Business Review 64(5), 53-59.

Ghemawat, P. (1999).

Strategy and the business landscape. Massachussets: Addison-Wesley.

Ghemawat, P. (2000).

A estratégia e o cenário dos negócios: textos e casos. Porto Alegre: Bookman.

Hair, J. F., Jr., Anderson, R. E., Tatham, R. L., \& Black, W. C. (1998). Multivariate data analysis (5th ed.). New Jersey: Prentice Hall.

Henderson, B. D. (1989).

The origin of strategy. Harvard Business Review 67(6), 139-144.
Johnson, J. T., \&

Busbin, J. W. (2000).

The evolution of competitive advantage: has virtual marketing replaced time-based competition? Indiana: Competitiveness Review.

Johnson, R. A., \&

Wichem, D. W. (1998).

Applied multivariate statistical analysis. New Jersey: Pearson Education Inc.

Kotler, P. (2000).

Administração de marketing. São Paulo: Prentice Hall.

Malhotra, N. (2001).

Pesquisa de marketing. Porto Alegre: Bookman

Mintzberg, H.,

Ahlstrand, B., \&

Lampel, J. (2000).

Safari de estratégia: um roteiro pela selva do planejamento. Porto Alegre: Bookman.

Mouritsen, J.,

Bukh, P. N.,

Larsen, H. T., \&

Johansen, M. R. (2002).

Developing and managing knowledge through intellectual capital statements. Journal of Intellectual Capital, 3(1), 10-29.

Ohmae, K. (1988).

Getting back to strategy. Harvard Business Review 66(6), 149-157.

Porter, M. (1989).

Estratégia competitiva: técnicas para analise de indústrias e da concorrência. Rio de Janeiro: Campus 
Prahalad, C. K., \&

Hamel, G. (1990).

The core competence of the corporation. Harvard Business Review 68(3), 79-92.

Prahalad, C. K., \&

Hamel, G. (1995).

Competindo pelo futuro: estratégias inovadoras para obter o controle do seu setor e criar os mercados de amanhã. Rio de Janeiro: Campus.

Quinn, J. B.,

Doorley, T. L., \&

Paquette, P. C. (1990).

Beyond products: services-based strategy. Harvard Business Review 68(2), 58-65.

Sanderson, S. M. (1998).

New approaches to strategy: new ways of thinking for the millennium. Management Decision 36(1), 9-13. Recuperado em junho, 2003, de http:/ /proquest.umi.com/pqdweb?sid= $1 \& \mathrm{RQT}=511 \& \mathrm{TS}=1195504972$ \&clientId $=18113 \&$ firstIndex $=90$
Stalk, G., Jr., \&

Hout, T. M. (1990).

Competing against time: how timebased competition is reshaping global markets. New York: The Free Press.

Selznick, P. (1971).

A liderança na administração; uma interpretação sociológica, Rio de Janeiro: FGV.

Urich, D., \& lake, D. (1990).

Organizational capability: competing from the inside out. New York:Wiley

Wheelwright, S., \&

Hayes, R. H. (1985).

Competing through manufacturing. Harvard Business Review 63(1), 99110.

Whittington, R. (2002).

$O$ que é estratégia. São Paulo: Pioneira Thomson Learning. 